\title{
HABEMUS CURSUM PHILOSOPHICUM
}

\author{
Lúcio Marques *
}

Resumo: Eis um artigo de divulgação que não só notifica a identificação de um manuscrito raro mas também analisa duas perspectivas prévias à consideração do manuscrito em si mesmo: o senso histórico na cultura brasileira e alguns elementos da cultura escolar colonial. A terceira parte apresenta e analisa os aspectos físicos e diagramatórios do manuscrito, além de apresentar a organização conteudística e elencar dados filológicos mínimos. Nessa apresentação, discurtiremos a seguinte hipótese: esse manuscrito pode ser considerado um Cursus Philosophicus semelhante aos cursus escritos em Coimbra ou Salamanca?

Palavras-chave: Manuscrito colonial. Colégio Serenense. Cursus Philosophicus. Mato Grosso.

Abstract: This article aims to divulge the identification of a rare manuscript. However, prior to considering the manuscript itself, the study will analyze the following two perspectives: the sense of history in the Brazilian culture and some elements of the colonial school culture. The third section will analyze the physical and diagramming features of the manuscript, present the organization of its contents and introduce some basic philological data. We propose the following hypothesis: can this manuscript be considered a Cursus Philosophicus similar to the cursus written in Coimbra or Salamanca?

Keywords: Colonial Manuscript. Serenense College. Cursus Philosophicus. Mato Grosso.

\footnotetext{
* Doutor em Filosofia pela Pontifícia Universidade Católica do Rio Grande do Sul; professor na Universidade Federal do Triângulo Mineiro. Artigo recebido em 02/06/2019 e aprovado para publicação em 27/10/2019.
} 


\section{Introdução}

consideração da história do ensino em nosso país, desde o período
colonial aos nossos dias, está envolta, de alguma forma, em supo-
siçóes pouco plausíveis, a saber, a recusa de existência de ensino superior no período colonial, a destruição dos escritos e bibliotecas coloniais inacianas, a proibição da existência de imprensa, etc. Além disso, reitera-se a crença na destruição das bibliotecas: "a grande perda que o Brasil sofreu com a dissolução da Companhia pode ser sentida na destruição das suas bibliotecas: quinze mil volumes se perderam no Colégio em Salvador, outros cinco mil no Rio de Janeiro, além de mais doze mil nos colégios do Maranhão e do Pará" (Hallewell, 2012, p. 80). A repetição dessas afirmações conduz, não poucas vezes, à crença de que não houve ensino superior nem imprensa no período colonial, além da destruição das bibliotecas e escritos provenientes dos colégios. Como não assentimos a tais afirmações sem considerandos, cremos necessário avaliar, sobretudo, um manuscrito colonial em vistas de ratificar a impossibilidade de aderir a tais afirmações sem um conhecimento sincero da história do ensino colonial. Por isso, nossa análise partirá de notas sobre o senso histórico na cultura brasileira passando à cultura escolar nacional e finalizaremos com a apresentação do Manuscrito 380 do Colegio Serenensi do Mato Grosso¹.

\footnotetext{
${ }^{1}$ Enumeremos alguns esclarecimentos: em primeiro lugar, a expressão Colegio Serenensi consta no manuscrito e como ainda não estamos fazendo uma revisão para editio critica, manteremos o original apesar de saber que a expressão correta seria Collegium Serenense. Quando à existência de um colégio no Mato Grosso no século dezoito é algo bastante difícil de documentar, por isso apresentamos e agradecemos os apontamentos feitos pelos professores João A. Mac Dowell, SJ, e Sandro Roberto da Costa, OFM. Tais apontamentos comporão um estudo mais amplo sobre a origem do manuscrito no futuro, por isso agora apenas pontuamos os demais esclarecimentos: em segundo lugar, o surgimento das primeiras vilas de Cuiabá (1723) e Vila Bela da Santíssima Trindade (1752) impõem uma dura questão sobre a origem do manuscrito, segundo Mac Dowell, "a quem iriam eles (os professores) ensinar filosofia em latim?" Terceiro, o uso do termo colégio era comum na tradição europeia e jesuítica, enquanto dominicanos e franciscanos quase sempre viviam em seus conventos e frequentavam o ensino "público", ainda segundo Mac Dowell e mais, Frei Sandro R. Costa desconhece uma presença mais significativa dos franciscanos naquelas terras no período, o que exigirá mais pesquisas para identificar a suposta filiação franciscana do manuscrito. Quarto, se a expressão Collegium Serenense designa a localidade de origem, seria pouco provável pensar alguma relação entre a cidade chilena de La Serena que se encontra a mais de dois mil e quinhentos quilômetros em linha reta em relação a Cuiabá, embora a Villanueva de la Serena tenha sido fundada em 1543 ou 1544. Quinto, interroga Mac Dowell, "como um manuscrito ali originado teria ido parar nas mãos de um frade português e seria depositado em um arquivo de Portugal?" Uma questão equivalente se aplicaria aos escritos do Catalogus Eborensis que apresentamos em 2018. Estudaremos essas questões na composição da história do manuscrito, mas surpreende o fato de existir tal manuscrito, de indicar o vulgo Mato Grosso como origem, de permanecer desconhecido por tanto tempo, de estar tão bem conservado, de não constar em nenhum catálogo de escritos lusitanos, porém em uma cultura que continua a repetir a suposta "destruição" das bibliotecas jesuíticas (Hallewell 2012, p. 80), resta-nos a paciente e confiante certeza de termos que estudar e escrever "a história da cultura escolar colonial" (Leite, 2006, VII, p. 224), porque o curso da história margeia o rio do esquecimento (léthe), mas não deve nele naufragar.
} 
E não apenas cremos a validade e excelência desse manuscrito, mas interpomos a seguinte hipótese: estamos diante de um Cursus Philosophicus escrito no período colonial?

\section{O senso histórico}

As Catilinárias de Marco Túlio Cícero constituem um dos melhores exemplos de sabedoria latina e, não por acaso, ele reconhece que a história é a magistra vitae. Com ela aprendemos a paciência do tempo e reencontramos o trabalho de outrora que nos chega como sabedoria para o presente. A maestria da história torna-se tanto mais importante quanto mais se esquece ou pretende-se esquecer o passado. Esse esquecimento não vem ao acaso. Antes, o esquecimento do passado resulta do longo processo de destruição da memória coletiva e das tradições orais. Isso se deve, em grande parte, à força do passado. Ele não apenas conserva os segredos através do silêncio das horas, mas também revela o inesperado. Por isso, as grandes culturas sempre se dedicam ao registro da história e à conservação do passado. Nesse sentido, temos culturas que se eternizaram na memória graças à narração da história de si para os outros. Essa narração de si acontece através dos textos, pinturas, esculturas, culinária, músicas, entre outras formas. A violência contra o passado acontece sempre pela destruição da memória, e os exemplos são abundantes: vide as ações do autoproclamado Estado Islâmico do Iraque e do Levante entre 2013 e 2015 que se estenderam da cidade histórica de Hatra ao Mausoléu de Imam Dur entre a Síria e o Iraque, os quais atingiram pelo menos treze grandes monumentos.

No Brasil, há um medo da memória, ou melhor, há uma luta pelo esquecimento que se caracteriza diretamente pela destruição da história e da memória museológica como explicitamente se reconhece na destruição do Museu do Ipiranga (2007), Teatro Cultura Artística (2008), Instituto Butantã (2010), Auditório do Memorial da América Latina (2013), Liceu de Artes e Ofícios de São Paulo (2014), Museu da Língua Portuguesa (2015) e Museu Nacional (2018). Infelizmente, a política de descaso com os museus revela uma perspectiva mais profunda, ainda que não tematizada: há uma luta pelo esquecimento do passado. Enquanto nas grandes culturas sempre houve ações contra o esquecimento do passado, no Brasil, o processo parece inverso. Olha-se o passado com receio e desconfiança, porque não se quer a história como mestra de vida. Não por acaso, há um contrassenso profundo em nosso descuido com o passado: por um lado, os países de economia neoliberal investem vultosamente em museus, coleções de objetos antigos e arte clássica e, por outro, em nosso país, graça o descuido generalizado com a memória. E não sendo fato novo, parece haver uma disposição latente ao apagamento da memória. 
Quando pensamos no conhecimento acerca da história do nosso país, parece haver mais pessoas interessadas em conhecer a história de outros países que a nossa história. O que, de certo modo, revela-se na baixa estima que temos pelo nosso passado. Embora entoemos no hino nacional paz no futuro e glória no passado, não nos parece evidente o reconhecimento das glórias passadas. Grosso modo, recorda-se o relato patético da vinda dos portugueses, folcloriza-se a imagem dos povos originários (indígenas), sensualiza-se os encantos das mulatas africanas e desmoraliza-se a vinda da família real para a colônia. Aliás, muito do que se conhece da ação portuguesa na colônia confunde-se, por um lado, com a corrupção dos degredados deixados nos trópicos e, por outro, com a dita corrupção carnavalesca da família real.

Frente a tudo isso, a aclamada glória do passado esvai-se como a memória de um país que não revela verdadeira estima pelo que foi nem pelo que é. Some-se a isso o ralo conhecimento da história colonial, imperial e republicana mesmo entre letrados. Essa deficiência no conhecimento histórico agrava-se em virtude da colonização epistêmica do saber, isto é, somos demasiado ciosos da visão que o europeu tem sobre o exotismo colonial, mas ainda não nos interrogamos seriamente sobre o que pensamos acerca do europeu. A primeira consequência disso mostra-se na abundância literária europeia sobre os trópicos que se estende desde a Carta de Pero Vaz de Caminha, os relatos dos navegantes e missionários como J. Léry, A. Thévet, N. D. Villegagnon, H. Staden até M. Montaigne, nem navengante nem missionário, mas que eternizou uma imagem do canibal até os nossos dias com belas obras como Le Brésil de Montaigne de F. Lestringant, A construção do Brasil na literatura de viagem dos séculos xvi, xvii e xviii de J. M. França Carvalho e os Tristes Trópicos de C. Lévi-Strauss. A segunda consequência é reversa: a dependência epistêmica em relação ao europeu colonizou nosso autoconhecimento. Por isso, uma necessidade imperiosa que se tem destacado nos últimos anos é, por um lado, uma hermenêutica pluritópica que interrogue nossa história não através das categorias europeias, mas principalmente das relações e saberes fundantes dos povos originários e dos africanos. Por outro lado, urge descolonizar a epistemologia para compreendermos o lugar histórico dos descolonizados na história do pensamento. Isso implica tanto a solidariedade com a história dos povos originários cuja dizimação chegou a noventa por cento da população no século dezesseis quanto fazer justiça à desterritorialização dos africanos jogados sob a chibata e depois à própria sorte sem nenhuma mudança de sua condição histórica, social e política. Em ambos os casos, não pensamos suficientemente a desumanização desses povos, por isso reiteradamente flertamos com o imaginário colonial.

Além disso, o parco senso histórico nos destrói por dentro: quer pela baixa estima histórica quer pela vulnerabilidade a que nos expomos por desconhecermos nosso passado. Essa carência não decorre da inexistência 
da história, mas por seu deliberado apagamento, e os exemplos não são insignificantes. Em primeiro lugar, repetimos facilmente que o povoamento e a escolarização do nosso território foram litorâneos e tardios. De fato, pensando na glória do passado do ouro e dos diamantes de Minas Gerais, surpreende saber que a primeira instituição de ensino nesse Estado data de 1750. Em segundo, a escolarização tardia e precária traz a má-fama de ter diplomado uma cifra de menos de dez por cento em relação ao ensino mexicano: "Só da Universidade do México sabe-se com segurança que, no período entre 1775 e a independência, saíram 7.850 bacharéis e 473 doutores e licenciados. É interessante confrontar este número com o dos naturais do Brasil graduados durante o mesmo período (1775-1821) em Coimbra, que foi dez vezes menor, ou exatamente 720."2 Note-se que o ensino colonial na América Portuguesa, segundo Sérgio Buarque de Holanda, não conferia graus, e a graduação anotada pelo autor seria em Coimbra. Em relação ao ensino superior no período colonial, não sem polêmica, escreveram-se várias obras e, de nossa parte, não apenas duvidamos da suposta inexistência de ensino superior no período colonial, quanto sugerimos outra hipótese. ${ }^{3}$ Em terceiro lugar, a reforma pombalina do sistema de ensino e a consequente expulsão dos jesuítas tem duas consequências drásticas: a primeira, a quase completa inviabilização do ensino colonial e a segunda, a repetida afirmação da "destruição quase completa" do que se retirou dos colégios. Naturalmente, o ensino colonial foi radicalmente danificado com a reforma e quase completamente inviabilizado, mas felizmente muito do que havia nos colégios foi preservado, inclusive escritos filosóficos, como tivemos a honra de demonstrar em A lógica da necessidade. Mas há ainda outra consequência nefasta que anotamos em quarto lugar: a carência de pesquisas sobre a história do ensino colonial. Exemplifico com o monumental Dicionário do Brasil Colonial organizado por Ronaldo Vainfas que em suas seiscentas páginas não registra nenhuma dessas entradas: escola, colégio, faculdade, professor e universidade. ${ }^{4}$ Embora seja o melhor dicionário para o que se propõe editado no Brasil, ainda assim indica uma profunda carência de desenvolvimento de pesquisas sobre o período colonial. É exatamente nesse sentido que notamos nossa falta de senso histórico comum. Talvez seja por isso que Serafim Leite advertia há seis ou sete décadas: "a história da cultura escolar colonial ainda não está feita em bases científicas, o que vem a significar que ainda não se estudou nas suas fontes, dentro do ambiente e dos livros que foram veículos dela." ${ }^{5}$

É justamente à história da cultura escolar colonial que temos nos dedicado e não sem espanto ou admiração, recordando o preciso sentido aristotélico do thaumázein, que nos vemos impelidos à busca de compreender o que

${ }^{2}$ HOLANDA, S. B. Raízes do Brasil. Rio de Janeiro: Aguilar, 2002, p. 1025.

${ }^{3}$ MARQUES, L. A. A lógica da necessidade. Porto Alegre: Fi, 2018, p. 83-123.

${ }^{4}$ VAINFAS, R. (org.) Dicionário do Brasil Colonial (1500-1808). Rio de Janeiro: Objetiva, 2000.

${ }^{5}$ LEITE, S. História da Companhia de Jesus no Brasil. Belo Horizonte: Itatiaia, 2006, VII, p. 224. 
se processou na história do ensino nesse território que hoje demonina-se Brasil. Mas, para não incorrer em impropriedades, necessário se faz averiguar o que se entende por cultura escolar no período colonial.

\section{A cultura escolar colonial}

Além do desenvolvimento tardio e litorâneo, a escolarização colonial foi obra do humanismo religioso. A saber, um ensino voltado, antes de tudo, à formação de hostes religiosas, cujo processo facultava-se em alguns casos aos estudantes externos. Em se tratando de formação religiosa, os cursos introdutórios eram praxe - Línguas Clássicas, Retórica, Humanidades para o bom proveito dos cursos filosóficos e teológicos. Cumpre notar que os estudos filosóficos regiam-se por uma praxe que se consolidou a partir dos séculos quatorze e quinze que estudava inicialmente a lógica, depois filosofia natural, ética e metafísica. ${ }^{6}$ A Ratio Studiorum formalizou o triênio de estudos lógicos, físicos e metafísicos sob os auspícios dos grandes mestres: Aristóteles e Tomás de Aquino. Note-se ainda o cuidado na observância dos costumes nas Províncias de Portugal e do Brasil quando este seguiria aquele em caso de interpretação duvidosa da Ratio. ${ }^{7} \mathrm{O}$ triênio filosófico destina-se, primeiramente, a ensinar a pensar corretamente, por isso o princípio pela lógica. Os estudos de filosofia natural incluíam desde a origem das coisas físicas às faculdades da alma, inclusive vontade, juízo e entendimento, o que conduzia aos estudos éticos. A conclusão do triênio operava a passagem da ética à metafísica e desta à introdução aos conhecimentos teológicos. Tanto a Ratio Studiorum quanto os Cursus Philosophicus Conimbricensis seguiam tal dinâmica, e a consequência era uma formação integral no melhor do humanismo renascentista como atesta: "a Filosofia apresenta uma tripla divisão: natural, moral e dialéctica, por ser tríplice a ordem das cousas que caem sob a sua alçada: as coisas físicas, que a razão não produz, mas só examina e pondera; as coisas mentais, que a razão patenteia a si mesma; as coisas da razão e da vontade em vista da procura do que for honesto e verdadeiro." ${ }^{8}$ Tudo isso afirmado grosso modo para que compreendamos o horizonte em que se movia o ensino colonial.

Grande parte do ensino colonial estava sob a responsabilidade dos jesuítas, e os escritos que conhecíamos até o presente proviam de sua lavra. O mérito dos inacianos foi imenso por terem não apenas fundado vários colégios litorâneos, mas terem registrado o que se ensinou. Esse

\footnotetext{
${ }^{6}$ MACINTYRE, A. God, Philosophy, Universities. Lanham, MA: Rowman \& Littlefield, 2011, p. 102.

${ }^{7}$ LEITE, op. cit., IV, p. 265.

${ }^{8}$ GOMES P. Os Conimbricenses. Lisboa: Guimarães, 2005, p. 150.
} 
registro não se encontra apenas na Ratio ou na História de S. Leite, mas em cinquenta escritos do período colonial. Na verdade, o primeiro que conhecemos data de 1747, do Colégio do Rio de Janeiro, outros trinta provêm do Colégio de Maranhão e dois do Pará. Felizmente, outros quinze dos Colégios de Coimbra e Évora. Tais escritos não se comparam à extensão dos Cursus Philosophicus et Commentarii de Coimbra, mas são uma fonte considerável de pesquisa. A feliz coincidência de haver escritos de Coimbra e Évora provenientes do mesmo período e com as mesmas características de conteúdo, extensão, referências e diagramação aporta uma informação importante, porque identifica o padrão comum de escrita e "publicação" dos dois lados do Atlântico. O fato dos escritos terem as mesmas características, inclusive semelhanças conteudísticas, evidencia uma prática comum nos colégios jesuítas e ainda mais, esse fato mostra que a expansão do ensino na Colônia não constituía uma espécie de exceção ou simplificação negativa. Ao contrário, mostra que as mesmas práticas e títulos equivalentes foram concedidos tanto em Coimbra e Évora quanto na Sicília e Maranhão, conforme documentamos oportunamente. ${ }^{9}$ Outro elemento que merece destaque refere-se aos procedimentos filosóficos e exegéticos. Os autores filosóficos mais frequentados eram os mesmos nos escritos coloniais e reinóis. Além disso, a sequência argumentativa não diferia da praxe normativa dos Cursus et Commentarii. Não apenas pela tríplice divisão, mas também pela lógica de alguns argumentos. Uma diferença notória refere-se aos escritos morais no que tange à escravidão: nos colégios do outro lado do Atlântico, as referências eram mínimas, mas deste lado, a discussão sobre a escravidão não só foi acalorada quanto suficientemente autônoma a ponto de criticar os conceitos de escravidão natural e de direito natural, por certo, com críticas ao aristotelismo-tomista.

Digno de nota é o desconhecimento de Cursus Philosophicus jesuíticos até o presente. Embora S. Leite referencie tais escritos em alguns pontos, ainda não se localizou nenhum exemplar, porém estamos suficientemente convictos de que essa seja apenas uma questão de tempo. Assim pensamos em virtude da quantidade de escritos provenientes do Maranhão e Pará e, nesse caso, a considerar a antiguidade e importância do Colégio da Bahia, somente com muito desfavor, não se teria escrito nenhum Cursus vel Commentarii em Salvador. Finalmente, note-se que a expansão dos colégios jesuíticos foi, de fato, litorânea, e a penetração no interior da colônia aconteceu tardiamente, sobretudo, a partir da segunda metade do século dezoito, e logo adveio a expulsão. E, para fazer justiça, anotemos algumas observações sobre a chegada missionária inaciana ao centro-oeste.

Nossa atenção deter-se-á na Capitania de Mato Grosso criada pela provisão de 9 de maio de 1748. Serafim Leite registra o tratamento dado aos povos originários de forma incisiva: "se encontrou há alguns anos a nação dos

${ }^{9}$ MARQUES, ob. cit., p. 101-15. 
Índios Parecis mui próprios para domesticar-se, com muitos princípios de civilidade, e outras nações de que se poderiam ter formado Aldeias numerosas e úteis; e, com sumo desprazer, soube que os sertanejos do Cuiabá não só lhes destruíam as povoações, mas que totalmente têm dissipado os meus Índios com tratamentos indignos de se praticarem por homens cristãos." $10 \mathrm{O}$ tratamento dado pelos ditos cristãos aos povos originários não parece diferir nas Américas Espanhola e Portuguesa e, ainda assim, note-se a civilidade daqueles povos cujo encontro com os inacianos datou de 12 de janeiro de 1751. As Instruções Régias que produziram o deslocamento de jesuítas de Porto Feliz no Tietê em direção a Cuiabá deveram-se tanto às razões de justiça e humanidade alegadas pela Coroa quanto à preocupação com a ação espanhola nas margens do rio Guaporé:

A incumbência, que os Padres levavam, por expressa ordem régia era difícil, nobilíssima sob o aspecto da justiça e da humanidade, oposta porém aos interesses materiais dos colonos, a saber, o aldeamento dos Indios livres, com exclusão dos indivíduos particulares que os exploravam; por outro lado, a incumbência tinha uma finalidade política, de aspecto territorial, a ocupação total das margens do Guaporé, onde os espanhóis se tinham parcialemente estabelecido, com as suas missões. Missões também de Jesuítas, que agora se achavam frente a frente, não como Jesuítas (função comum religiosa) mas como portugueses e espanhóis (função patriótica divergente), procurando uns e outros os interesses das respectivas pátrias, como funcionários de Estado, que eram realmente, com o encargo oficial do aldeamento dos Índios. ${ }^{11}$

A justiça e humanidade da Coroa em relação aos povos originários justificava-se pelo temor de perda dos domínios territoriais para a Coroa Espanhola. O historiador não se ilude quanto ao reconheicmento da brutalidade dos colonos lusitanos contra aqueles povos. Os colonos os tiranizaram e devastaram impiedosamente e receberam respostas, senão equivalentes, pelo menos em mesmo tom. Porém, àqueles que souberam tratá-los, sabiam igualmente cultivar a sociabilidade: "os Índios reagiam "como feras" contra quem os tratava como feras; e "como homens" sociáveis, com quem os tratava como homens, com habilidade e brandura". ${ }^{12}$ Ademais, a ambiguidade colonial não se reduzia ao páreo jesuíta-colono, mas entre os detentores da função comum religiosa opunham-se aqueles com função patriótica divergente. Malgrado tudo isso, nota-se ainda a brutalidade da ação colonial nas palavras relatadas por Leite: "em quanto ao mais, que Vossa Reverência me faz favor referir, do estado das Missões dessa Província e Capitania, digo que como são determinações reais as quero supor justas; mas quererem os homens dar aos Índios o juizo, que Deus Nosso Senhor não quis que eles tivessem, ninguém acabará comigo o tenha por bem."13

\footnotetext{
${ }^{10}$ LEITE, ob. cit., VI, p. 216-217

${ }^{11} \mathrm{Ib}$. VI, p. 219.

${ }^{12} \mathrm{Ib}$. VI, p. 221.

${ }^{13} \mathrm{Ib}$. (itálico inserido).
} 
Destacamos anteriormente a folclorização da compreensão dos povos originários, mas o projeto colonial não se reduziu a isso. A folclorização foi precedida pela destruição da compreensão dos povos originários como seres humanos. A suposta carência de juízo não apenas evidencia a compreensão datada da metade do século dezoito, mas coincide ainda e exatamente com a suposta ignorância insuperável atribuída aos povos originários nos relatos do século dezesseis. Justamente por esse motivo - a perpetuação da visão dos povos originários como carentes de juízo e como dotados de uma ignorância insuperável -, que se faz necessário deslocar o eixo interpretativo da visão formada pelo europeu para uma autocompreensão dos povos originários. Ainda que essa tarefa seja demasiado árdua, se quisermos compreender os povos originários e africanos e, de fato, nos compreendermos, precisamos descolonizar nossos princípios epistêmicos e buscar compreendê-los à luz dos raros e preciosos escritos e costumes remanescentes dessas duas matrizes antropológicas. Essa tarefa é, provavelmente, uma perspectiva das mais frutíferas em vistas de integrar não apenas a visão de mundo proveniente dos povos originários, africanos e europeus que nos constituem, mas integrar a história dos povos tupi-guaranis com a história dos maias, astecas e incas que nos precederam nesse continente. Enfim, o limiar da pesquisa jesuítica aponta três ciclos missionários inacianos no Mato Grosso: um espanhol, um português e um brasileiro. ${ }^{14}$ Por óbvio, esses ciclos têm uma importância digna de pesquisa, no entanto, a datação dos ciclos é suficiente para as seguintes inferências: a primeira, o ciclo brasileiro aconteceu depois da restauração da Companhia; a segunda, o ciclo lusitano foi demasiado recente em relação a 1756 e breve (1751-1759) a considerar a instituição do colégio; o ciclo espanhol não foi suficientemente estruturado a ponto de estabelecer um colégio no Mato Grosso. Com isso, a consideração da história do ensino nas margens do Cuiabá e do Guaporé não foi obra inaciana e, justamente dessa origem que ainda desconhecemos, veio o Manuscrito 380 recentemente localizado e que descrevemos na sequência.

\section{Manuscrito $\mathbf{3 8 0}$}

A mestra da vida é também um oceano profundo de surpresas. Heráclito de Éfeso afirmou também com grande sabedoria (fr. 18): "se não se espera, não se encontra o inesperado, sendo sem caminho de encontro nem vias de acesso." $\mathrm{O}$ inesperado desconcerta nossas certezas, revela nossa ignorância e torna arenoso o solo sob nossos pés. Essa elegante tradução elaborada por Emmanuel C. Leão mereceu um elegante comentário de

${ }^{14} \mathrm{Ib}$. p. 224. 
Donaldo Schüler: "se o encontro com o esperado se consumasse, os caminhos se apagariam, secariam os rios que navegamos e que nos atravessam, perderíamos sem recurso os cursos e dormiríamos embalados no silêncio das origens." O inesperado talvez seja tão importante à filosofia quanto a admiração aristotélica, porque ele nos ensina a enxergar para além do casual. Exatamente, o sussurro do inesperado mantém a chama da pesquisa acesa e daí, possivelmente, decorrem grandes descobertas. E mais, a crença no inesperado talvez seja o princípio que conduziu gênios como Marie Curie e Stephen Hawking a persistirem na busca da radioatividade e dos buracos negros. Mas, sinceramente, por mais que cresse no inesperado, julgaria pouco provável localizar um manuscrito tão importante e completo fora do eixo litorâneo de expansão dos colégios.

O inesperado deve-se justamente à ausência quase completa de referências ao dito Colegio Serenensi, vulgo do Mato Grosso, donde provém o Manuscrito 380 que contém 871 fólios escritos, e recebido pelo Fr. Emmanuel ab Angelis (Manuel dos Anjos) e iniciado em 15 de novembro de 1756. Apenas no fólio 457 aparece na parte superior o nome de Fanera Fonceca, mas não se indica qualquer relação com o manuscrito. Não encontramos maiores indícios de proveniência quanto à ordem que o originou, mas somos levados a crer que seja franciscano segundo informações preliminares recebidas da pesquisadora lusitana Maria Camps, a quem agradeço efusivamente. Outro indício de franciscanismo teórico refere-se à tríplice indicação de Joanis Duns Scoti presente no início de cada livro do manuscrito, cujo título geral é Compedium Philosophicum... Ademais, avançamos nossa hipótese interpretativa: este é um Cursus Philosophicus similar aos Cursus Conimbricensis. Não apenas pela extensão do manuscrito, mas sobretudo pela exposição sistemática do conteúdo. Embora estejamos fazendo uma leitura apenas de reconhecimento, há indícios suficientes para termos as melhores expectativas quanto a esse manuscrito. Malgrado o desconhecimento tanto da história do Colegio Serenensi quanto do Fr. Emmanuel ab Angelis e, principalmente, do escritor, há uma série de informações que merecem imediatamente nossa atenção.

O manuscrito digitalizado contém 871 fólios escritos além de outros em branco, e cada fólio apresenta, em média, 37 linhas com 75 caracteres em cada linha, o que mostra um pouco o tamanho relativamente maior que a paginação em uso atualmente. O manuscrito está em ótimo estado de conservação e leitura, o que facilita consideravelmente a pesquisa. Todos os parágrafos estão numerados à margem em arábicos, e a numeração recomeça a cada quaestio. Outro elemento curioso são as abreviaturas e nas quais predominam duas características básicas: o uso do trema - nä, aüm, mä e aïa abreviando, respectivamente, natura, actum, materia e ani$m a$, e o uso do sublinhado ou sobreescrito - divisiob, p ëe, qd e verbo abreviando, respectivamente, divisionibus, per esse, quomodo e verborum. Além disso, há nove ilustrações no primeiro livro com estrita função 
didática, a saber: a primeira (fl. 040) caracteriza funções proposicionais entre subalternans e subalternatas, contrariae e subcontrariae e contrariae e contradictoriae, sendo um explanação exata das normas dos silogismos. A segunda (fl. 046) apresenta os elementos da precedente, acrescendo as oposições entre quatro categorias: necesse e possibile, possibile e impossibile. A terceira (fl. 053) exemplifica as doze primeiras figuras modais diretas dos raciocínios que permitem conclusões assertivas. A quarta (fl. 054) continua a precedente, exemplificando as figuras modais indiretas, além da segunda e terceira figuras modais diretas dos raciocínios conclusivos. A quinta (fl. 062) talvez seja o melhor exemplo didático em uso no manuscrito e destina-se ao treino mnemônico e à compreensão dos raciocínios lógicos universais afirmativos e negativos, e particulares afirmativos e negativos. A sexta (fl. 159) apresenta a Arbor Phorphirii estruturada quase como um símbolo cabalístico em três colunas, sendo a esquerda e a direita (lidas na vertical de alto a baixo) destinadas aos incorpóreos, inanimados, indemonstrável e irracional. A coluna central reservada (lida de baixo para cima) às espécies ínfimas, animais, viventes, corpos e substância do gênero supremo. Cada elemento conecta-se a outros em relações verticais, horizontais e transversais. A sétima (fl. 185) apresenta a tabela de divisões dos antepredicamentais a partir de quatro vértices: as substâncias universal e singular, e os acidentes universal e singular. A oitava (fl. 187) exemplifica os nove predicamentos numerados sequencialmente com exceção natural da substância, enquanto gênero supremo. A nona (fl. 197) apresenta a constituição dos entes mundanos a partir da composição e derivação da substância completa, dos entes corpóreos, dos entes corruptíveis e dos elementos. E, finalmente, enquanto características gerais: o manuscrito constitui um compedium philosophicum completo com um texto revisto. Pela estruturação e clareza da apresentação, nota-se que o recompilatum foi, a bem da verdade, uma revisão editorial em linguagem e formas atualizadas. $\mathrm{O}$ manuscrito subdivide-se em três livros - lógica, física e metafísica. Cada livro estrutura-se em tratados: sendo nove tratados de lógica, quatro de física e o livro de metafísica que, por não conter mais de um tratado, não foi numerado. Os tratados estruturam-se em distinções somando trinta e quatro ao todo. As distinções, por sua vez, estruturam-se em noventa e quatro questões e estas, em duzentos e sessenta e oito capítulos. Por todas essas características, seria improvável não se tratar de um cursus philosophicus completo com edição revista (recompilatum).

Além dos proêmios que introduzem os livros, há um prôemio geral dedicado à explanação geral do conceito de filosofia e nele, a primeira questão trata da natureza, qualidades e propriedades da filosofia e a segunda questão destina-se às causas eficiente, formal e material da filosofia (fólios 003-013). O primeiro livro trata de toda a lógica exposta em nove tratados, a saber: o primeiro, a súmula lógica considera as três operações do conhecimento - o intelecto, o juízo e o discurso; o segundo, a grande lógica abordada 
em sua natureza, objeto e qualidade; o terceiro, os entes de razão considerados a partir de sua essência, existência e multiplicidade; o quarto, os universalis em geral e em espécie; o quinto, os predicamentos abordados desde os antepredicamentos aos predicamentos em particular e as partes dos predicamentos; o sexto, a interpretação considera na primeira distinção o signo e a voz e na segunda, a enunciação; o sétimo, consignado em distinção e questão únicas trata do silogismo em geral, ou melhor, dos Primeiros Analíticos; o oitavo, define a ciência e as formas de demonstração considerando os Segundos Analíticos; o nono tratado destina-se aos Tópicos e Elencos e analisa os silogismos hipotético e elênquico. Os nove tratados (fólios 014-280) evidenciam claramente a exposição completa da lógica prometida no título.

O segundo livro trata da física (folios 281-819) e merece destaque, já de início, a extensão que ocupa no número de fólios. O primeiro tratado aborda os oito livros da Física de Aristóteles, e o destaque centra-se nas oito distinções: os princípios das coisas naturais; os princípios intrínsecos do ser das coisas naturais; a natureza física; as causas exemplar, eficiente e final; o contínuo, o infinito e o movimento; o lugar e o vazio; o tempo; e o princípio e divisão das coisas naturais. Como se nota no título, o autor cumpre a exposição dos livros físicos do Estagirita. O segundo tratado, sobre o mundo, estrutura-se em três distinções: a constituição do mundo e dos corpos simples em comum (entenda-se: aspectos gerais); o céu e os corpos celestes; e os elementos em comum. O terceiro tratado, sobre a corrupção em geral e em comum, aborda na primeira distinção a alteração em espécie, ou seja, a mudança e, na segunda distinção, a geração e a corrupção. $\mathrm{O}$ quarto tratado, sobre a alma, apresenta três distinções: a alma em comum; a alma vegetativa e sensitiva; e a alma racional.

O terceiro livro dedicado à metafísica (fólios 820-871) não apresenta a subdivisão de tratados, por ser único, mas três distinções: na primeira há três questões que tratam, respectivamente, da natureza da metafísica e do ente; do ente em geral; e das partes dos entes. A segunda distinção consta como quaestio unica sobre a existência dos entes finitos. A terceira distinção apresenta duas questões: a distinção entre substância e acidentes e os acidentes.

Não há uma proporção exata na distribuição do número de fólios por livro, mas as exposições não parecem deficientes pela mesma razão. A extensão do segundo livro deve-se, provavelmente, ao duplo caráter teórico que o compõe: a constituição das coisas físicas e éticas. Outros elementos que merecem destaque são as referências teóricas: indiscutível o scotismo manifesto no início de cada tratado, mas não despreza em momento algum a leitura atenta de toda a filosofia aristotélica como se nota diretamente nos temas dos tratados e distinções. Há referências diretas a Platão e Porfírio e, de forma especial, destaquem-se as considerações presentes no primeiro 
capítulo da quaestio apendicae à segunda disputa do tratado sobre a alma em que consta o seguinte título: quid sentiant moderni circa animae essentiam. A res cogitans cartesiana é citada e analisada teórica e praticamente em suas consequências, além de ser confrontada aos conceitos de alma provenientes dos peripatéticos e à conceituação unívoca scotista. Com esses elementos provenientes de uma leitura inicial e voraz, cremos serem suficientes para a apresentação e divulgação do manuscrito.

\section{Considerações gerais}

Doravante, iniciam-se os maiores desafios: a transcrição em forma de editio diplomatica, seguida de uma análise filológica e o estabelecimento do texto em uma editio critica e, finalmente, a tradução e o comentário do manuscrito. Paralelamente, precisamos pesquisar tanto a história do Colegio Serenensi do Mato Grosso quanto a autoria do texto. Por óbvio, dada a escassez de informações de que dispomos, aproveitaremos para buscar outras referentes à sociedade e ao desenvolvimento do Mato Grosso em relação às condições que originaram o manuscrito. Ademais, em breve, apresentaremos outros manuscritos de que temos apenas notícias até o presente. Enfim, como resultados parciais das pesquisas que temos realizado, alguns elementos tornam-se patentes: o primeiro, a dita destruída do patrimônio cultural proveniente do período colonial não aconteceu como um todo. Antes, parece haver mais que o imaginado nas bibliotecas e arquivos lusitanos. Segundo, a advertência do historiador inaciano sobre a necessidade de estudar a história da cultura escolar colonial em suas fontes não apenas é válida, mas urgente, e cremos estar apenas nos seus traços iniciais. Terceiro, considerando a expansão dos colégios coloniais e a antiguidade de suas fundações, provavelmente, quando se localizarem os arquivos do Colégio da Bahia, estaremos diante de um dos maiores tesouros da história educacional do país. Este talvez seja um dever imperioso: a necessidade de continuarmos a pesquisa sobre a história do ensino no Brasil, isto é, a história dos desenvolvimentos social, político e cultural das populações que formaram o país que hoje ainda somos se a faina destrutiva dos governos não conduzi-lo à convulsão social. Quarto, houve e ainda há uma recusa explícita da história nacional. $\mathrm{O}$ descaso ou menosprezo em relação à nossa história desde a colônia aos nossos dias não soa casual, mas causal. Nesse sentido, haveria uma política de esquecimento que permeia a cultura brasileira a qual se estende desde o descaso com os museus à tentativa de apagar o passado. Longe de querermos idealizá-lo, porque somos céticos quanto à paz no futuro e glória no passado. Não temos dúvidas de que a história não apenas é a mestra da vida, mas Cícero ainda tem muito mais a nos ensinar com suas Catilinárias: "a história é testemunha do passado, luz da verdade, vida da memória, 
mestra da vida, anunciadora dos tempos antigos." Por isso, impõe-se a nós, os brasileiros, se quisermos entender adequadamente o valor e o sentido do ensino, da colônia às investidas governamentais contra o sistema de ensino público, cabe-nos a tarefa de superar a política do esquecimento e da negação do passado, porque, diz ainda Cícero, "o homem que não conhece a História é um menino."

\section{Referências}

CÍCERO, M. T. Catilinárias. Lisboa: 70, 1989.

GOMES, P. Os Conimbricenses. Lisboa: Guimarães, 2005.

HALLEWELL, P. O livro no Brasil: sua história. São Paulo: USP, 2012.

HOLANDA, S. B. Raízes do Brasil. Rio de Janeiro: Aguilar, 2002.

LEITE, S. História da Companhia de Jesus no Brasil. Belo Horizonte: Itatiaia, 2006.

MACINTYRE, A. God, Philosophy, Universities. Lanham, Ma: Rowman \& Littlefield, 2011.

MARQUES, L. A. A lógica da necessidade. Porto Alegre: Fi, 2018.

VAINFAS, R. (org.) Dicionário do Brasil Colonial (1500-1808). Rio de Janeiro: Objetiva, 2000.

Endereço do Autor:

R. Azevedo Costa, 60, Bloco 1. Apto. 402

B. Boa Vista

38017-130 Uberaba - MG 